\title{
Catheter Directed Thrombolysis in Management of Acute Thrombotic Lower Limb Ischemia
}

\author{
MOHAMMED H. ABD EL-ATY, M.Sc.; AMR M. ABO RAHMA, M.D.; \\ MOHAMMED A. EL-HENIEDY, M.D. and ADEL H. KAMHAWY, M.D. \\ The Department of Vascular Surgery, Faculty of Medicine, Tanta University
}

\begin{abstract}
Background: Acute limb ischemia is a limb threatening condition that require wise decision making to achieve limb salvage.

Aim of Study: To evaluate the safety, efficacy and outcome of catheter directed thrombolysis (CDT) in management of acute thrombotic lower limb ischemia.

Patients and Methods: 20 patients suffering from acute limb ischemia (ALI) due to infrainguinal arterial thrombosis were submitted to catheter directed thrombolysis under fluoroscopic guidance, treated by Actilyse "tissue plasminogen activator" during the period from April 2017 to April 2018, outcome was assessed by angiographic imaging "technical success" and clinical improvement "clinical success".
\end{abstract}

Results: Overall thrombolysis success and limb salvage were achieved in 16 patients $(80 \%)$, major amputation was performed in 4 cases $(20 \%)$, surgical interference "thrombectomy" was needed in 2 cases $(10 \%)$, complementary balloon angioplasty was done in 4 cases $(20 \%)$. Regarding complications, peri-sheath hematoma was observed in 5 patients $(25 \%)$, one case developed compartment syndrome $(5 \%)$, epistaxis in 2 cases $(10 \%)$ and hematuria in 3 cases $(15 \%)$, no mortality recorded during hospital stay or two weeks follow-up.

Conclusion: Catheter directed intra-arterial thrombolysis is a safe, effective management for thrombotic etiology of ALI.

Key Words: Acute limb ischemia - Catheter directed thrombolysis - Thrombolytic therapy - Thrombosis.

\section{Introduction}

SURGICAL intervention in the form of thrombectomy/embolectomy, bypass or amputation has been the traditional treatment option for ALI until the 1990 s, when endovascular treatment by thrombolytic agents gradually took place [1]. For patients experiencing arterial embolism, surgical throm-

Correspondence to: Dr. Mohammed H. Abd El-Aty, The Department of Vascular Surgery, Faculty of Medicine, Tanta University boembolectomy is a simple procedure with high success rate, but for patients with arterial thrombosis on top of PAD the results are different [2] . Disadvantages of surgical intervention in those patients include endothelial injury, inability to remove the thrombus from infra-popliteal arteries and thrombosed collateral vessels, leaving the underlying lesion responsible for thrombosis untreated and high risk of mortality when performing major surgery in those critical patients with much comorbidities [3].

Advantages of CDT over surgery include lower mortality risk; it's done with local anesthesia, better accessibility to smaller arteries, identifying the underlying lesion, allow correction of this lesion by endovascular means in the same session and ultimately avoidance of major amputation [4] Selection of treatment strategy depend on many factors; the severity and etiology of ischemia, duration of symptoms, location of the occlusion and the general condition of the patient [5]. Rutherford's classification is the most commonly used grading system for severity of ALI [6]. Only patient with Rutherford's category I (viable) and IIa (marginally threatened) are suitable for CDT [7]. ALI of duration more than 2 weeks has shown less response to CDT [8]. Other limitations include presence of contraindication to thrombolytic agents [9].

\section{Patients and Methods}

The study included 20 patients admitted at vascular surgery department, Tanta University Hospital, in the period from April 2017 to April 2018.

Inclusion criteria: Patients included in the study are those with thrombotic ALI on top of PAD, with occlusion in (distal SFA, popliteal or infra-popliteal 
arteries) who were presented with category I and IIa according to Rutherford's classification of ALI "viable and marginally threatened" in which duration of ischemic event is 14 days or less. These are highly selective inclusion criteria to gain maximal cost-benefit from the relatively expensive CDT.

Exclusion criteria: Patients with embolic ALI, those with Rutherford's category IIb and III "immediately threatened and irreversible ischemia", and patients having contraindications to thrombolytic agents.

All the recruited patients were subjected to complete history taking and physical examination including examination of both lower limb arterial pulsations, motor and sensory examination, ankle brachial pressure index (ABPI) measurement and other signs of ALI. Duplex study and CT angiography have been done to all studied patients, both have role in treatment selection, detection of level and length of occlusion and differentiation between thrombotic/embolic etiologies. The study was approved by the ethical committee of the Faculty of Medicine in Tanta University. A written informed consent was taken from all patients after detailed description of the procedure before enrollment in the study.

\section{Technical details:}

The procedure was performed in the angiosuite under local anesthesia. Under fluoroscopy, ipsilateral ante-grade puncture of common femoral artery is used for sheath placement. Initial angiogram is performed, to visualize the morphology, location and the extension of the lesion, the outflow of the occluded artery, and the run-off vessels (Fig. 1). A 0.035 inch, hydrophilic coated guidewire (Terumo Co., Japan), is inserted through the sheath to cross the thrombus (Fig. 2), crossing of the guidewire through the lesion (positive guidewire traversal test) is a predictor of success of the procedure. Then the guidewire is advanced to the target runoff vessel which was visualized in the initial angiogram. When the guidewire has crossed the lesion, the thrombolytic catheter is placed (Fig. 3). A 5Fr Unifuse catheter (Angiodynamics Inc., USA) with side-holes is used, the infusion length of the catheter is the length of the segment with side-holes, this segment is placed within the thrombus. An occluding wire prevents kinking and provides the proper force to activate pressure response outlets. The Unifuse catheter with the occluding wire allow equal pressure distribution throughout the catheter resulting in equal distribution of lytic agent. Forceful diffusion of the thrombolytic material diluted in saline by manual shots cause thrombolysis by two mechanisms; mechanical fragmentation of the thrombus, increasing the exposed surface area of the thrombus, and pharmacological effect of the thrombolytic agent dissolving the thrombus. The sheath is secured, then the patient can be transferred and the lytic therapy is started. The thrombolytic drug used was (Alteplase, Actilyse, Boehringer Ingelheim, Germany), one vial contains $50 \mathrm{mg}$, Intrathrombus bolus (10mg) is administered through the catheter, followed-by low-dose continuous infusion (1.5mg every 1 hour), each dose is diluted in $20-50 \mathrm{ml}$ saline. Systemic intravenous anticoagulation with unfractionated heparin is started immediately, in sub-therapeutic dose $(6 \mathrm{U} / \mathrm{kg} / \mathrm{h})$ to maintain the APTT to 1.25 to 1.5 of control. During the infusion, the patient is closely monitored for development of complications, bleeding as hematoma around the sheath, loss of sensory or motor functions and development of compartment syndrome. The patient is transferred again to the angio-suite every 10 hours or depending on clinical assessment, fluoroscopic imaging is done. Finally, after an angiographic imaging demonstrating no signs of significant residual occlusion (Fig. 4), heparin infusion can be stopped and the sheath can be removed after normalization of APTT within 2 to 3 hours.

\section{Endpoints of the procedure:}

The procedure was aborted if there was complete dissolution of the thrombus with restoration of flow, complete dissolution with persistent underlying stenosis requiring balloon dilatation, development of major complication, exceeding the accepted dosage limits (40mg for Actilyse), or progression to irreversible (category III) ischemia.

After the procedure patients were evaluated by pain improvement, capillary refilling, motor and sensory functions, pulse state, Doppler arterial flow and ankle brachial pressure index (ABPI). Technical success is defined as complete lysis of the occluding thrombus with restoration of the blood flow to the foot. Clinical success is defined as relief of the acute ischemic symptoms and avoidance of major amputation.

Combination of two categories of antiplatelet drugs were used, low dose aspirin (150mg/day) with cilostazol (100mg/day in 2 divided doses). Patients were asked to come once weekly for 1 month. 
(A)

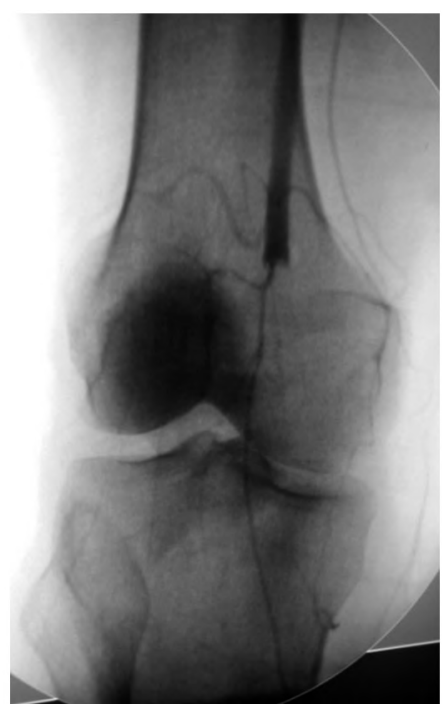

\section{(B) CI NE 1}

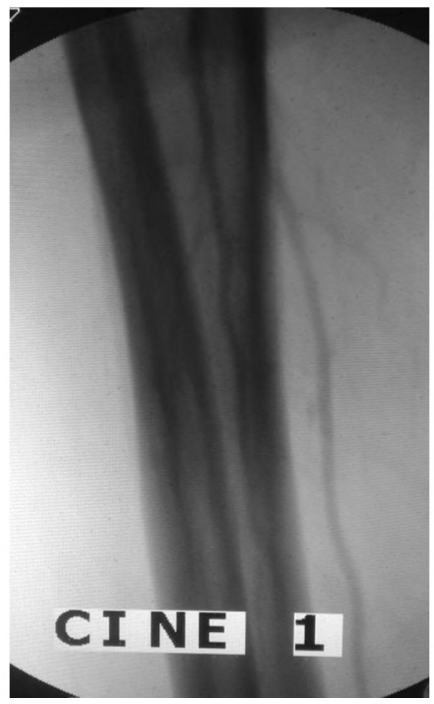

Fig. (1): Initial angiogram showing popliteal artery thrombosis (A) with patent infrapopliteal distal runoff arteries (B).

(A)



(B)



Fig. (2): The guidewire crossing the thrombus in popliteal artery (A) and run distally to the anterior tibial artery $(\mathrm{B})$

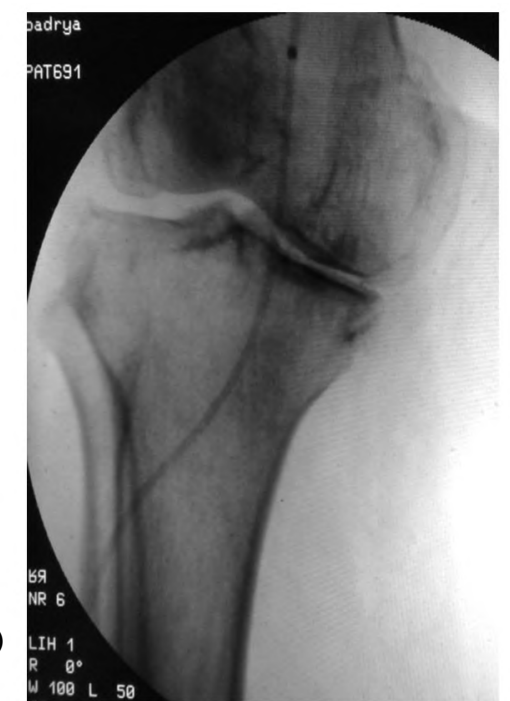

(B)



Fig. (3A,B): The upper and lower ends of the infusion length of the catheter. 


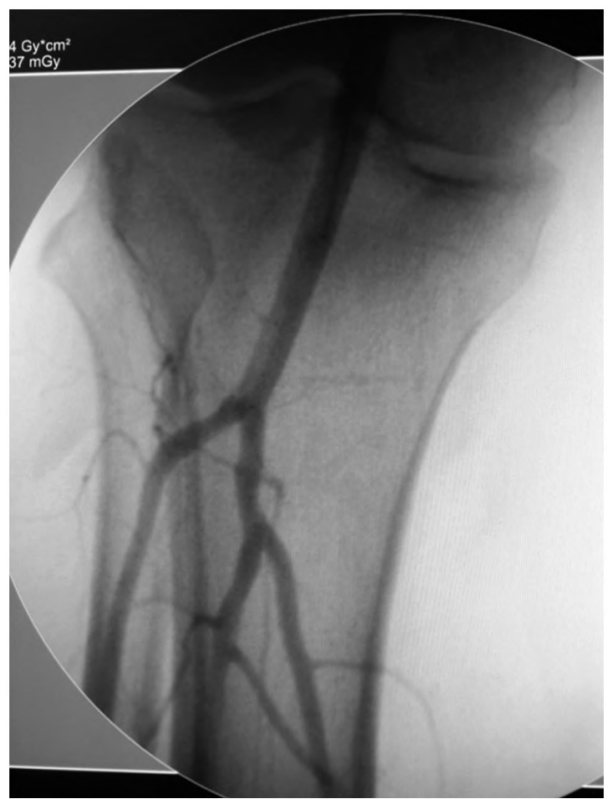

Fig. (4): Imaging of the arterial system show complete dissolution of the occluding thrombus and restoration of the blood flow after 20 hours of Actilyse infusion.

\section{Results}

This study that was carried out on 20 patients with acute thrombotic lower limb ischemia, all treated with catheter directed thrombolysis. There were $11(55 \%)$ males and 9 (45\%) females, age varied between 44 years to 67 years with mean age of 54 years. The most common associated comorbidities were diabetes, hypertension and smoking as their incidence were $60 \%, 40$, and $40 \%$ respectively. The majority of cases (16 cases) presented with category IIa ALI, (80\%), while only 4 cases presented with category I ALI (20\%). All patients included in this study were complaining of ALI of duration 14 or less, the duration ranged from two to 14 days with mean duration of 7 days. Fifteen patients were presented with popliteal thrombosis detected in the pre-procedure duplex study and CT angiography (85\%), while three cases presented with distal SFA thrombosis (15\%) and 2 patients with infra-popliteal arteries occlusion. In eighteen patients included in the study $(90 \%)$, there was at least one distal runoff artery detected in the pre-procedure CT angiography, while in 2 cases only there was no detectable distal runoff vessel $(10 \%)$. All data are summarized in Table (1).

As regard complications, among the twenty cases included in the study, five cases developed hematoma around the sheath $(25 \%)$ but only one of them was large hematoma, which made it mandatory to abort the procedure. One case developed

compartment syndrome in which the procedure was aborted and fasciotomy was done (5\%), epistaxis was observed in 2 cases $(10 \%)$, and hematuria in 3 cases $(15 \%)$.

As regard response to thrombolysis, 15 cases (75\%) achieved technical and clinical success after completing CDT. Among those 15 cases, five cases (20\%) needed complementary balloon angioplasty to correct underlying stenosis. Two cases showed residual thrombus after completing the procedure with incomplete clinical improvement in which surgical intervention was performed, one of the two cases improved after thrombectomy only without bypass, the other case did not improve after femoral-popliteal bypass and below knee amputation (BKA) was done. The remaining 3 cases showed no thrombus dissolution (absence of technical success) nor clinical improvement (absence of clinical success), no trial of surgical intervention in these 3 patients because two of them had no detectable distal runoff vessels and the third patient had severe chest infection with bad general condition so did not tolerate surgery, above knee amputation (AKA) was done to these 3 cases later. Therefore, overall thrombolysis success in our study was achieved in 16 cases $(80 \%)$ which improved clinically and major amputation was avoided. All results are summarized in Table (2).

Table (1): Demographic data, risk factors and criteria of included patients.

\section{Demographic data}

Age

Gender (M:F)

Risk factors and co-morbidities:

Diabetes

Controlled hypertension

Heavy smoking

Ischemic heart disease

Previous stroke

Compensated hepatic failure

Atrial fibrillation (AF)

Rutherford's classification:

Category IIa

Category I

Duration of symptoms:

Duration in days

Runoff vessels:

Detectable

Non detectable
$54(44-67)$

11:9

$8(40 \%)$

$8(40 \%)$

$5(25 \%)$

$3(15 \%)$

$2(10 \%)$

$2(10 \%)$

$16(80 \%)$

$4(20 \%)$

$2(10 \%)$ 
Table (2): Outcome of the study.

Complications:

Peri-sheath hematoma $\quad 5(25 \%)$

Hematuria $3(15 \%)$

Epistaxis $2(10 \%)$

Compartmental syndrome $\quad 1(5 \%)$

Additional interventions required:

Balloon angioplasty $\quad 4(20 \%)$

Thrombectomy $2(10 \%)$

Bypass $1(5 \%)$

Fasciotomy $1(5 \%)$

BKA $1(5 \%)$

AKA $3(15 \%)$

Response to thrombolysis:

Overall success $\quad 16(80 \%)$

Failed thrombolysis $\quad 4(20 \%)$

\section{Discussion}

Three clinical trials provided definitive evidence that patients with acute limb ischemia had clinical benefit from CDT, Rochester study [10], Surgery versus Thrombolysis for Ischemic Lower Extremity (STILE) trial [8], and the thrombolysis or peripheral arterial surgery (TOPAS) trial [11]. The consensus from these studies was that CDT should be firstline treatment for ALI under the following conditions: Where symptoms of limb ischemia present for 14 days or less, there are no absolute contraindications for thrombolysis and patients with $\mathrm{Ru}-$ therford's category I and IIa ischemia. In this study, the etiology of ALI was exclusively thrombotic; embolic cases of ALI were excluded, this exclusion is consistent with some other studies including the STILE trial [8]. In other studies including the TOPAS trial [11], Nilssen et al., [1] and Urbak et al., [12], patients with both thrombotic and embolic etiologies were subjected to CDT. This highly selective study involved only patients with thrombosis in distal SFA, popliteal an infra-popliteal arteries, those patients get the most benefit from CDT. It has been found that results of conventional surgery for the treatment of acute popliteal and tibial arteries thrombosis remain poor. Thromboembolectomy with the Fogarty catheter is currently used to remove an occluding arterial thrombus located in iliac, femoral arteries with relative good results. However, when thrombus located in the popliteal artery and the trifurcation, this procedure may fail. This was explained by incomplete extraction of clot from popliteal and tibial arteries because of the angulated origins of the tibial arteries. In such cases, popliteal artery exposure is necessary which needs general anesthesia, putting the patient at risk of major surgery. In cases of infragenicular occlusive arterial disease, thromboembolectomy presents the potential dangers of perforation of tibial arteries with subsequent hemorrhage, pseudoaneurysm or arteriovenous fistula formation [3] Another reason for our selection of cases with distal thrombosis is the higher risk of distal embolization during iliofemoral thrombolysis, the risk of distal embolization in endovascular procedures of the superficial femoral artery (SFA) is around $10 \%[13]$

As regard co-morbidities in this study, Diabetes Mellitus (DM) was the most common risk factor (60\%). In contrast, STILE investigators [8] and Plate $\mathrm{G}$ et al., [14] found that heavy smoking is the most common risk factor for ALI. This can be explained by higher incidence of DM in Egypt which is around $15.6 \%$ of all adults aged 20 to 79 , this is caused by obesity, lack of physical activity, dietary habits and Chronic Hepatitis C Infection [15].

The ipsilateral ante-grade approach for femoral artery was preferred in this study, advantages of this approach are availability with lower cost and the decrease in the access-to-lesion distance, which in turn improves the mechanical advantage and responsiveness of the tools used to perform the intervention [16].

The thrombolytic agent used in this study was (Alteplase, Actilyse, Boehringer Ingelheim, Germany), it is a recombinant tissue plasminogen activator, although it's high cost it was the drug of choice over Streptokinase and Urokinase due to its fibrin specificity and therefore higher efficacy with less bleeding complication [17]. Various techniques for thrombolytic agent delivery are recorded, including intrathrombus bolusing or lacing, continuous infusion, graded infusion, stepwise infusion and pulse spray technique. Intrathrombus highdose bolusing or lacing followed by low-dose continuous infusion, the chosen technique in this study, is easy applicable and highly effective strategy [18]. In this study, $10 \mathrm{mg}$ bolus of Alteplase was used followed by $1.5 \mathrm{mg} /$ hour continuous infusion. In Semba et al., a Society of Interventional Radiologists (SIR) advisory panel recommended a maximum dose for Actilyse of $2 \mathrm{mg} / \mathrm{h}$ and a maximum total infusion of 40mg [19]

Amputation free survival rate of $80 \%$ was achieved with percutaneous catheter directed thrombolysis, STILE investigators [8], Nilssen et al., [1] and Urbak et al., [12] had achieved amputation free survival rate ranging between 69 to $90 \%$. Ansel GM et al., [20] and Zehnder T. et al., [21] combined CDT with percutaneous mechanical thrombectomy; they achieved an amputation free survival rate reaching $92 \%$. 
Bleeding complications occurred in $30 \%$ of studied cases, all presented with minor bleeding except one case; this is considered high in comparison to other trials as Nilssen et al., [1]. Urbak et al., [12] and Ligers et al., [22], in which bleeding complications ranged between 5 to $19 \%$. This can be explained by the higher dose of thrombolytic drug used in comparison to other studies and lower patients compliance. A high dose of rtPA accelerates the thrombolysis and achieves the faster restoration of blood flow. It is a potential advantage to patients with acute ischemia where the time interval is essential, but there is a higher rate of bleeding complications. The risk of bleeding must be assessed against the risk of surgery or amputation before the CDT for every patient [22]. However, in this study, only one case (5\%) developed major bleeding in the form of non-controllable epistaxis, hematuria and large hematoma around the sheath, the procedure was aborted. All other bleeding complications were managed conservatively with neither aborting the procedure nor blood transfusion. More restrictive inclusion criteria, close monitoring and early detection of bleeding might explain the low rate of life threatening hemorrhage. Distal embolization was not recorded in this study as a complication of CDT; this is most probably due to selection of cases with distal occlusions only. Distal embolization is reported as a complication of ilio-femoral thrombolysis. Until 2016, catheter-directed thrombolysis with concomitant use of embolic protection devices has not been previously reported in lower extremity arteries; Irani demonstrated the use of embolic protection device in lower extremity catheter-directed thrombolysis in four patients with SFA thrombosis [13]

There was no mortality as a direct result of thrombolysis in this study, there was no incidence of intracranial hemorrhage, although they were reported in other studies as Nilssen et al., [1] and Urbak et al., [12]. This study may have been too small to encounter this complication.

Four cases involved in the study needed major amputation, three above knee and one below knee. It was noticed that the four cases were having acute ischemia of relatively longer duration (11 to 13 days) before CDT; also two of them had no detectable distal runoff vessel, Sandbaek G et al., [23] Nilssen et al., [1] and Urbak et al., [12] had previously noticed that absence of distal runoff has a bad impact on outcome.

\section{Conclusion:}

It has been concluded that thrombolysis is an effective, less-invasive alternative treatment to surgery in the management of the acutely ischemic limb. However, this minimally invasive option should be used for selected patients.

\section{Reference}

1- NILSSEN G.L., SVENDSEN D., SINGH K., et al.: "Results of catheter-directed endovascular thrombolytic treatment of acute ischaemia of the leg". Eur. J. Vasc. Endovasc. Surg., 1, 41 (1): 91-6, 2011.

2- CREAGER M.A., KAUFMAN J.A. and CONTE M.S.:" Clinical practice. Acute limb ischemia." N. Engl. J. Med., 366 (23): 2198-206, 2012.

3- DESGRANGES P., KOBEITER K., D'AUDIFFRET A., et al.: "Acute occlusion of popliteal and/or tibial arteries: The value of percutaneous treatment." Eur. J. Vasc. Endovasc. Surg., 20 (2): 138-45, 2000.

4- HYNES B.G., MARGEY R.J., RUGGIERO N., et al.: "Endovascular management of acute limb ischemia" Ann. Vasc. Surg., 26 (1): 110-24, 2012.

5- GOLDSTEIN J.A. and MISHKEL G.: "Choosing the correct therapeutic option for acute limb ischemia". J. Interv. Cardiol., 3.3: 381-389, 2011.

6- RUTHERFORD R.B., BAKER J.D., ERNST C., et al.: "Recommended standards for reports dealing with lower extremity ischemia: Revised version”. J. Vasc. Surg., 26 (3): 517-38, 1997.

7- FUKUDA I., CHIYOYA M., TANIGUCHI S., et al.: "Acute limb ischemia: Contemporary approach". Gen. Thorac. Cardiovasc. Surg., 63 (10): 540-8, 2015.

8- STILE Investigators. "Results of a prospective randomized trial evaluating surgery versus thrombolysis for ischemia of the lower extremity". Ann. Surg., 220: 251-68, 1994.

9- Working Party on Thrombolysis in the Management of Limb Ischemia. "Thrombolysis in the management of lower limb peripheral arterial occlusion-a consensus document”. J. Vasc. Interv. Radiol., 14 (9 Pt 2): S337-49, 2003.

10- OURIEL K., SHORTELL C.K., DEWEESE J.A., et al.: "A comparison of thrombolytic therapy with operative revascularization in the initial treatment of acute peripheral arterial ischemia". J. Vasc. Surg., 1, 19 (6): 1021-30, 1994.

11- OURIEL K., VEITH F.J. and SASAHARA A.A.: “A comparison of recombinant urokinase with vascular surgery as initial treatment for acute arterial occlusion of the legs, Thrombolysis or Peripheral Arterial Surgery (TOPAS)”. N. Engl. J. Med., 16, 338 (16): 1105-11, 1998.

12- URBAK L., de la MOTTE L., RORDAM P., et al.: "Catheter-Directed Thrombolysis in the Treatment of Acute Ischemia in Lower Extremities Is Safe and Effective, Especially with Concomitant Endovascular Treatment". Ann. Vasc. Dis., 25, 10 (2): 125-31, 2017.

13- IRANI Z. and OKLU R.: "The use of embolic protection device in lower extremity catheter-directed thrombolysis". Diagn Interv Imaging, 97 (2): 273-5, 2016.

14- PLATE G., JANSSON I., FORSSELL C., et al.: "Thrombolysis for acute lower limb ischaemia-a prospective, randomised, multicentre study comparing two strategies". Eur. J. Vasc. Endovasc. Surg., 1, 31 (6): 651-60, 2006. 
15- HEGAZI R., EL-GAMAL M., ABDEL-HADY N., et al.: "Epidemiology of and risk factors for type 2 diabetes in Egypt". Ann. Glob. Health, 1, 81 (6): 814-20, 2015.

16- WAGNER J., GANDHI R.T. and POWELL A.: "Technical Approach to Antegrade Femoral Access". Tech. Vasc. Interv. Radiol., 18 (2): 82-6, 2015.

17- LYDEN S.P.: "Endovascular treatment of acute limb ischemia: Review of current plasminogen activators and mechanical thrombectomy devices". Perspect. Vasc. Surg. Endovasc. Ther., 22 (4): 219-22, 2010.

18- KESSEL D.O., BERRIDGE D.C. and ROBERTSON I. "Infusion techniques for peripheral arterial thrombolysis". Cochrane Libr., 1, 2004.

19- SEMBA C.P., MURPHY T.P., BAKAL C.W., et al. "Thrombolytic therapy with use of alteplase (rt-PA) in peripheral arterial occlusive disease: Review of the clinical literature”. J. Vasc. Interv. Radiol., 1, 11 (2): 149-61, 2000.
20- ANSEL G.M., GEORGE B.S., BOTTI C.F., et al.: "Rheolytic thrombectomy in the management of limb ischemia: 30-day results from a multicenter registry". J. Endovasc. Ther. Aug., 9 (4): 395-402, 2002.

21- ZEHNDER T., BIRRER M., DO D.D., et al.: "Percutaneous catheter thrombus aspiration for acute or subacute arterial occlusion of the legs: How much thrombolysis is needed?". Eur. J. Vasc. Endovasc. Surg. Jul., 1, 20 (1): 41-6, 2000.

22- LIGERS A., IVANOVA P., BERGS G., et al.: "Outcomes and Complications after Intraarterial Thrombolysis for Limb Ischemia: A 4 Year Study at a Single Centre". Acta. Chirurgica Latviensis, 1, 16 (2): 3-7, 2016.

23- SANDBAEK G.1, STAXRUD L.E., ROSÉN L., et al.: "Intra-arterial thrombolysis in peripheral bypass and arterial occlusions. Results and predictive factors for thro- mbolysis". J. Norweg. Med. Assoc., 116: 3000e4, 1996.



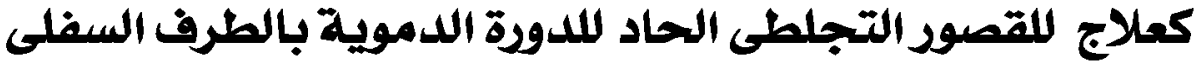

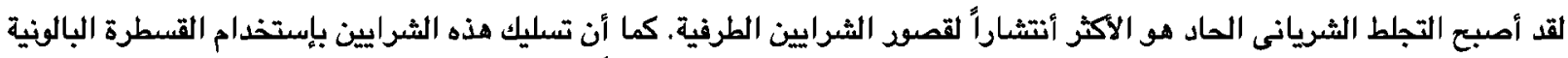

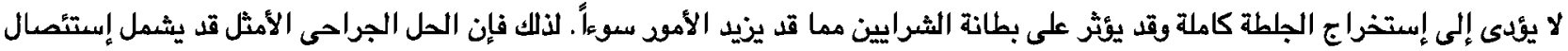

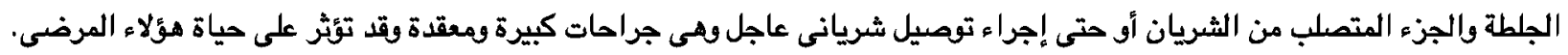 \\ إذابة الجلطات الثريانية بإستخدام القسطرة التداخلية يمثل البديل الأمثل لعلاج الحالاتالبسيطة والمترسطة فى تذيب الجلطة وتساعد \\ فى التعرف على سبب الجلطة كما تمكن من علاج السبب بإستخدام القسطرة التداخلية التلية. \\ أجرى هذا البحث على · r مريض يعانون من قصود حاد بالدوة الدموية اللطرف السفلى وقد كان الغرض من البحث دراسة هدى فاعلية

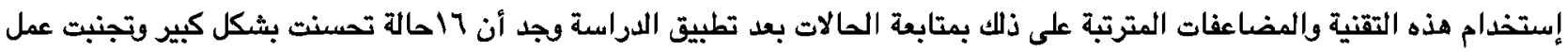



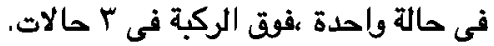

نستخلص من هذه الدراسة أنه على الرغم من التكاليف المرتفعة لعملية إذابة الجلطات إلا أنها توفر نسبة نجاح مرتفعة لحالات مختارة ممن يعانفن من أنسداد شريانى حاد قد لا توفرها الجراحة التقليدية. 